\title{
Analysis on Management Mode of Aquatic Innovation and Entrepreneurship Base of Domestic Colleges
}

\author{
He Shan, Cao Haipeng and Tan Hongxin \\ Fisheries and Life Science College, Shanghai Ocean University, Shanghai 201306, China \\ s_he@shou.edu.cn, hxtan@ shou.edu.cn
}

\begin{abstract}
This paper analyzes the construction status of innovation and entrepreneurship bases by domestic universities in respects of organization establishment, institutional guarantee and school-enterprise cooperation. Furthermore, this article proposes three advantages which are embodied in fields of students' individual development, resource utilization elevation and transformation between innovation and entrepreneurship program and describes the implement approach in the course of aquatic innovation and entrepreneurship base construction by colleges and local aquaculture administrative department, in order to explore a characteristic innovative management mode of aquatic innovation and entrepreneurship base.

Index Terms - Aquatic innovation and entrepreneurship base, Management mode, Construction by colleges and local aquaculture administrative department.
\end{abstract}

\section{Introduction}

In the context of high-speed development in economy and society, as the continuous upgrading and transforming of economic structure, the social demand for talents has gradually become diversification and complex. It's raised in the 18th National Congress of CPC that it's necessary to take technological innovation as the core in the development when implementing innovation driven strategy which is the strategic sustentation for social productivity and comprehensive national power elevation. Shanghai Ocean University has established aquatic innovation and entrepreneurship base and provided a practice platform for aquatic talents cultivationin innovation and entrepreneurship with the vigorous support of Shanghai Educational Committee in responding to the national policy. This paper takes the constructional path of innovation and entrepreneurship bases of domestic colleges as references and raises the construction idea of aquatic innovation and entrepreneurship bases in order to offer valuable advices for other similar colleges inland in founding innovation and entrepreneurship bases.

\section{The Significance of Innovation and Entrepreneurship Base Construction}

\subsection{The need to support national development}

The magnificent goal was released in the 18th National Congress of CPC which is to sharply raise the contributive rate of scientific-technical progress to economic growth and to create a innovative-oriented country [1]. While innovative talents come out in succession only when we have a preferable system in cultivation, utilization, flow and management of innovative talents. Innovative talents cultivation is the primary link of innovation management mechanism which plays a crucial fundamental role in constructing innovative country.

\subsection{The need to supply social talents}

Facing to the transformation and upgrading of our nation, society and industry, innovation is the best choice for enterprises to develop and grow stronger. Staffs with innovation spirit can bring more profit and value for enterprises by inspiration and originality motivated in daily work. Therefore the innovative talents cultivation has positive significance in promoting management and technology upgrading and in driving the society forward.

\subsection{The need to develop students' comprehensive literacy}

The cultivation and elevation of innovative literacy meet students' internal need for individual development and are also the starting point of innovation and entrepreneurship bases. The contradiction between educational resources and student quantity brought by the college enrollment expansion can be relieved by the educational resources of innovation and entrepreneurship bases to some extent, so as to better meet the need of students' self-development.

\section{The Constructional Path of Domestic College Innovation and Entrepreneurship Bases}

Nowadays, quite a lot of universities and vocational colleges have already founded innovation and entrepreneurship bases while different colleges pay attention to different points which can be summarized into two mainstreams of business incubator pattern and innovationbusiness pattern. The business incubator pattern focuses on students' entrepreneurial ability and provides supports in the respect of educational content. Take the Xi'an Financial Services Institute as example, it appreciates the business incubator and provides students with services such as facilities, credit granting and image promoting by serial mechanism of social undertaking development platform, exchange and cooperation platform and business platform so as to accelerate students' entrepreneurial process [2]. Vocational colleges pay more attention to the practicability of training content which can be demonstrated by the example of Zhejiang Vocational College of Commerce. It mainly carries out the E-business training which draws support from school's setting up the computer technology platform and trains students in terms of online shop opening, E-business website designing and animation production. The innovation and entrepreneurship base of innovation-business pattern not only 
assists students' business passion but also supports students to take part in innovation competitions and other activities. No matter any kind of college has its own management mechanism and experience of the innovation and entrepreneurship base and organizes activitiesmainly in four pathways as follows.

\subsection{To set up committees}

The innovation and entrepreneurship base is generally supervised by the vice president in charge and comprises management committee whose members are functional department leaders who make macro-supervision and resource allocation. Some colleges operate the innovation and entrepreneurship base depending on a certain institute when it sets a secondary leadership group under the management committee which comprises institute leaders whose job is to make specific measures and regulations for administration. Innovation and business service center can be set under leadership group and the service center can comprises innovation and business guidance office, project assessment office, financial management office quality supervision office and administrative office according to the need. Besides, some colleges purposely set up the program assessment expert panel who are composed by academic leaders and relative department heads whose work is to evaluate programs' process and outcome.

\subsection{To safeguard by system}

Under the collaborative management of teaching affair department and student administration department, colleges make a series of innovation and entrepreneurship base management systems including the base constitution, base operation measures, facility utilization rules, reward measures for innovative competition participation, innovation credits regulations, laboratory utilization measures and so on. Some colleges tighten teachers' professional title appraisal and take the students' prizes in innovation competitions who were guided by them as a fixed target [3]. Furthermore, some colleges operate business programs in an analogue simulation condition and these programs need to be monitored in respects of market behaviors including industry and commerce status, finance situation, tax payment and risk control, and it's needed to lay out certain regulations.

\subsection{To implement college-enterprise cooperation}

The college-enterprise cooperation patter is one of the most common patterns to construct college innovation and entrepreneurship bases which enjoys the merit of connecting pre-service education and post-service education and the merit of running through academic education and vocational training. This pattern can transport numerous high-quality innovative talents to enterprises when elevating students' innovative literacy by virtue of social power. Nowadays many colleges send students to enterprises to carry out production practice and invite successful entrepreneurs to give a lecture so as to acquaint students with modern equipment andtechnology. The college-enterprise cooperation pattern profits both the college and enterprise in respect of talents training and talents recruitment which can explain why it has become one of the most important ways in college talents cultivation.

\section{The Reflection and Exploration on Construction Mode of Aquatic Innovation and Entrepreneurship Bases}

Nowadays there exist several bottlenecks in the management process of domestic college innovation and entrepreneurship bases generally. Firstly, the faculty remains to be strengthened. The college innovation and entrepreneurship base relies on the faculty of its own in general while local teachers not only shoulder heavy tasks on instruction and scientific research but also have shortcomings on practical experience of innovation and business which will lead to a situation they feel exhausted and powerless to guide students in the innovation competition participation although they are willing to. Secondly, the resources utilization rate of innovation and entrepreneurship bases is relatively low. Many colleges take the equipment procurement as the main content of base construction while how to use these equipments fairly, effectively and scientifically is rarely regulated. Thirdly, the prospect of innovation and business programs is unknown. When a innovation program concludes it always ends, and the business program has relatively low success ratio among which failed programs come to nothing. Besides the students who take part in the innovation and business programs only account for a small percentage of the total, thus we should arouse students' interest and attract more people to dedicate to the programs and increase the input-outcome ratio. Based on the above analyses, it's in urgent need to considerate and explore the construction mode of aquatic innovation and entrepreneurship bases. The local aquaculture administrative department has rich experience and management advantages on the fishery production management, sci-tech popularization, fishery resources administration, environment and aquatic wildlife protection, fishery safety in production. Therefore the college and local aquaculture administrative departments launch extensive cooperation and expand thought can lead to a characteristic construction mode of innovation and entrepreneurship bases.

4.1 The management advantages of the construction mode by the college and local aquaculture administrative departments

\subsubsection{To benefit the cultivation of students' individual ability and expansion of employment channels}

Students come into contact with aquaculture professional skills and strengthen their practical ability when they are carrying out programs at bases which can both deepen their professional feelings and improve the intra-professional employment rate. What's more, this mode will provide support to the local farmers and solve problems for them, at the same time it's good for us to win public praise and expand the employment channels for the aquatic graduate.

\subsubsection{To benefit the conversion and connection between innovation programs and business programs \\ Students always take the local difficult problems in realistic practice of aquatic bases as the research topic when}


launching their innovation programs. When students find out solutions to the problems or the program comes to conclude, the problem solution can help to the local fishery production, thus the innovation program has the potential of commercial opportunity to success. For example, if a student finds out the cause and treatment to some disease happened in local aquaculture environment, it can always publish theses or has patent authorized and then it's hopeful to get these achievement commercialized and industrialized further more.

\subsubsection{To benefit to elevate the resource utilization ratio of base equipments}

Since it's to cooperate with the local aquaculture administrative departments to construct innovation and entrepreneurship bases, some equipment that existed are not necessarily purchased repeatedly and the equipments can be used by both scientific researchers of local administration and students carrying out innovation programs which can boost the resource utilization of equipments and facilities. On the other hand, students can ask local production and research personnel for advice and communicate with them so as to enrich the knowledge origins and enlarge their information tentacles.

\subsection{The implementation approach of innovation and entrepreneurship bases co-constructed by colleges and local aquaculture administrative departments}

\subsubsection{To take the aquatic strong countries as the prime choice for innovation and entrepreneurship bases}

t's suggested to give priority to aquatic hundred strong countries and ecological demonstration countries with dense industrial atmosphere and solid aquaculture foundation. The aquaculture-developed areas do better in advanced technology, strong condition, broad space, enormous scale, deep culture, favorable experience environment of aquaculture, thus it can provide aquatic professional education and instruction with the most realistic cases.

\subsubsection{To take the local aquaculture administrative \\ departments as the innovation and entrepreneurship base co-constructor}

Local aquaculture administrative departments connect closely and frequently with local farmers and provide them with consulting service and other assistance of aquaculture technology, genetic breeding, nutritive feed, disease control, water quality monitoring and aquatic product quality safety examination which will offer mature conditions for students' production practice, aquaculture investigation and aquatic skills training.

\subsubsection{Undergraduates enter bases to carry out innovation and business programs}

When undergraduates come to the local aquaculture administrative departments of countries and towns, they start to learn the production process and aquatic skills. At the same time they stay close to local farmers and communicate with them when students enhance the aquaculture experience and deepen the professional attachment. Students can also draft and write their dissertations when carrying out programs.
What's more, there're advanced modern equipments in local aquaculture administrative departments by which undergraduates can go out sampling, conduct experiments and scientific research and publish academic papers finally.

\subsubsection{To take the innovation and entrepreneurship base as a faculty construction platform}

dhering to the concept of invite in and step out, colleges can communicate with grassroots experts and entrepreneurs and employ them as tutors. Through the connection, the college teachers in charge of innovation and business guidance can come to the grassroots to investigate the industry status so as to better guide students to start entrepreneurship. Colleges can also send young backbone teachers to grassroots to take a temporary post so as to elevate faculty's comprehensive literacy on and on. Besides, some colleges invite successful entrepreneurs and famous scholars to give a innovation or business lecture and establish the innovation and business tutor bank which can help to forge an interdisciplinary teaching faculty and create favorable innovation and business atmosphere.

\subsubsection{To perfect the innovation driving mechanism and stimulate students' enthusiasm on innovation and entrepreneurship}

Colleges can combine the innovation and entrepreneurship driving mechanism with the professional training plan formulation and set up corresponding innovation credits. We can suggest students to publish academic papers and declare patents and participate in different kinds of innovation and business competitions and activities under tutors' guidance, and even the achievements they acquired can be converted to the innovation and business credits. Meanwhile we're perfecting the management mechanism of Undergraduate Innovation Program including application, accreditation, policy supporting and reward system by holding competitions. In addition, we vigorously reward students who are outstanding in competition and pay attention to the innovation activity broadcasting among students especially the freshmen.

\subsubsection{To provide entrepreneurship with thorough and detailed supporting service}

Colleges can provide students who are launching entrepreneurship with supporting services such as convenient living facilities and logistics service areas where students can organize logistics, warehousing and transportation. Furthermore, kinds of entrepreneurship simulation can be adopted such as the innovation street, creative studio, the innovative lecture and so on.

\section{Acknowledgements}

This work, in correspondence with Tan Hong-Xin, is contributed equally by Cao Haipeng and financially supported by Program of Shanghai Municipal Education Commission (No. B-5008-13-0003) and 085 project (No. B-5008-12-01014). 


\section{References}

[1] Report of 18th National Congress of CPC [EB/OL]. http://www.xj.xinhuanet.com/2012-11/19/c_113722546.htm

[2] G. Yan, "Research on the establishment and development mode of undergraduate innovation and business incubation bases," Journal of Jilin Radio and TV University, vol. 36, no. 10, pp. 26-27, October 2011.
[3] G. He, "Exploration on undergraduate innovation and business driving practice by innovation base construction," Journal of Changchun University of Science and Technology, vol. 32, no. 6, pp. 11-12, June 2011. 